\title{
Amparo por Ixs pibxs de la plaza: la sentencia, 12 años después ${ }^{1}$
}

Legal action for protection for the kids of the plaza: the sentence, 12 years later

\author{
Martin Menestrina ${ }^{2}$, Martina Flaherty ${ }^{3}$, Manuel \\ Rodríguez ${ }^{4}$, Antonela Coroli ${ }^{5}$ y Lucía Belaunzarán 6 \\ Universidad Nacional de La Plata - Argentina
}

Revista Derechos en Acción ISSN 2525-1678/ e-ISSN 2525-1686

Año 5/N 17 Primavera 2020 (21 septiembre a 20 diciembre), 437-449

DOl: https://doi.org/10.24215/25251678e466

Recibido: 01/09/2020

Aprobado: 15/11/2020

"Si no abrís la cabeza, no te crece el corazón"”

\section{Los hechos}

En el 2008 vivían alrededor de 200 niñxs en situación de calle en la ciudad de La Plata. El desinterés por parte del Estado, que se constataba en la falta de infraestructura, recursos, la

\footnotetext{
1 Los autores son miembros del Programa de Extensión “Niñez, Derechos Humanos y Políticas Públicas" de la Facultad de Ciencias Jurídicas y Sociales (UNLP).

2 Abogado (UNLP), Especialista en Derecho Procesal Profunizado (Universidad Notarial Argentina) (ORCID: https://orcid.org/0000-0002-2554-259X).

3 Abogada, (UNLP).

4 Psicólogo (UNLP).

5 Abogada (UNLP).

6 Licenciada en trabajo social (UNLP).

7 Consigna enunciada por niñxs y jóvenes de la Asamblea el Hambre es un Crímen 2017 y 2018.
} 
cancelación de programas que tenían como objeto trabajar con este grupo de niñxs, hizo que lxs mismxs se encuentren sin ninguna protección institucional.

Frente a esta compleja problemática era indispensable, tal como lo indica la ley 12.398 , la realización de un abordaje integral en el que intervinieran profesionales idónexs, junto con adultxs de la confianza de lxs niñxs para lograr restablecer lazos de comunicación y afecto que permitieran la realización de abordajes adecuados a los problemas concretos que presentaban cada unx de estxs chicxs. Sin embargo, pese a los distintos tipos de reclamos -formales e informales- a los Estados municipal y provincial solo se encontró silencio o respuestas insuficientes por parte de los organismos encargados de proteger los derechos de lxs niñxs.

En este marco de desamparo se formó la organización Autoconvocadxs por los Derechos de lxs Pibxs en situación de Calle, integrada por organizaciones sociales y de derechos humanos, instituciones académicas y personas interesadas en la problemática de la niñez, algunas de las cuales ya venían trabajando con los niñxs. De las diferentes estrategias efectuadas para visibilizar la crudeza del reclamo, se destacó una intervención conocida como "olla popular" que se llevó a cabo en algunos días de la semana, durante las tardes y noches en la Plaza San Martín, justamente donde se ubicaba una glorieta, donde esos niñxs solían dormir.

Luego de cuatro días en que se venía llevando a cabo la olla popular, el 25 de julio de 2008, un grupo de personas vestidas de civil, algunxs de ellxs identificándose verbalmente como policías, armadxs con palos, cadenas y armas de fuego golpearon y lesionaron a los 15 niñxs que se encontraban en la glorieta de la Plaza San Martín de La Plata.

Ese terrible hecho de represión, demostró la paradoja de que el Estado criminalizaba a estxs niñxs por hechos que tenían su origen en la omisión de haber implementado acciones integrales e inclusivas de derechos humanos. En tal contexto, un 
grupo de madres, organizaciones sociales e instituciones académicas promovieron una acción de amparo -con el patrocinio de algunxs miembrxs del Programa "Niñez, Derechos Humanos y Políticas Públicas"- contra la Provincia de Buenos Aires y la Municipalidad de La Plata solicitando la efectiva puesta en marcha de la ley 13.298 que había creado el Sistema de Promoción y Protección de los Derechos del Niñx (SPPDN).

\section{El proceso judicial}

El 14 de octubre de 2008 se dio inicio a la acción de amparo caratulada como "ASOCIACIÓN MIGUEL BRU Y OTROS C/ MINISTERIO DE DESARROLLO SOCIAL Y OTROS S/AMPARO” que tramitó en el Juzgado Contencioso Administrativo $N^{\circ} 1$ del Departamento Judicial La Plata, en ese entonces, a cargo del Dr. Luis Arias. El proceso judicial fue sumamente complejo, insumió de más de 20 "cuerpos" de expedientes de 200 "fojas" (páginas cada uno) y se tardó 4 años en arribar a una decisión.

Fue así como el 22 de mayo de 2012 el juez dictó una extensa sentencia condenando a la Provincia de Buenos Aires y a la Municipalidad de La Plata. En la misma, el juez tuvo por probado que "Como consecuencia de la pruebas reseñadas, emerge como una constante la escasa cantidad de recursos, la precariedad de las intervenciones, la falta de protocolos de actuación y la construcción diaria de estrategias basadas en las convicciones propias que los operadores tienen respecto de la implementación de la Ley 13.298. Sin desmerecer la encomiable tarea de algunos operadores de calle dependientes de la Dirección de Niñez y Adolescencia de la Municipalidad de La Plata -pues la Provincia, más allá de algún abordaje aislado, no ha demostrado ningún trabajo en territorio- queda claro que las intervenciones relatadas -por buenas que sean sus intencionesno están sustentadas en políticas públicas serias que permitan un trabajo coherente y sostenido en el tiempo...En síntesis, la presente causa refleja una tendencia a la construcción de políticas y programas centrada en la esfera retórica, que se 
renueva con el cambio de cada gestión, y que luego no tienen un impacto directo ni son capaces de transformar la vida de los niños que habitan la calle en la Ciudad de La Plata. Todo lo dicho evidencia una imposibilidad absoluta de elaborar políticas con criterios de integralidad, universalidad, e interdependencia entre los diversos organismos, por lo que juzgo sobradamente acreditado que en el ámbito de la Ciudad de La Plata no existen políticas eficaces de protección y promoción de derechos para la niñez y la adolescencia ${ }^{8}$."

Con esos fundamentos, hizo lugar a la acción de amparo y se condenó a la Provincia de Buenos Aires y al Municipio de La Plata a que, en el plazo de seis meses, realicen las acciones necesarias para la efectiva implementación de la ley 13.298 del Sistema de Promoción y Protección Integral de los Derechos del Niño.

Cabe mencionar que en la sentencia se trazó un plan para que las demandadas comenzaran a hacer efectiva la ley 13.298. Así, se señaló como parte de la condena la obligación de:

1. Crear uno o más Paradores con suficiente infraestructura y personal idóneo para cubrir las necesidades básicas de los niños, niñas y adolescentes que requieran esta asistencia, disponible durante las veinticuatro (24) horas del día.

2. Crear un Servicio Hospitalario Especializado para la atención de la salud de niños con problemas de adicciones u otras afecciones a la salud, que garantice la atención adecuada durante las veinticuatro (24) horas del día.

3. Disponer la cantidad de automotores necesaria para efectuar todos los traslados que requieran los niños en situación de vulnerabilidad que se encuentren en la ciudad de La Plata.

4. Implementar un servicio de atención telefónica destinado a la recepción de denuncias vinculadas con la vulneración de

8 ASOCIACION CIVIL MIGUEL BRU Y OTROSC/ MINISTERIO DE DESARROLLO SOC PCIA BS AS Y OTRO/A S/ AMPARO Sentencia de $1^{\circ}$ instancia 22 de mayo de 2012 
derechos de los niños, niñas y adolescentes, durante las veinticuatro (24) horas del día

5. Garantizar la disposición de operadores de calle en cantidad suficiente.

6. Difundir ampliamente en los medios de comunicación masiva de mayor circulación en la ciudad de La Plata, los principios, derechos y garantías de los niños, niñas y adolescentes consagrados en el ordenamiento jurídico, a cuyos efectos, las Administraciones condenadas deberán afectar un porcentaje no inferior al veinticinco por ciento (25\%) de todas las partidas presupuestarias destinadas a publicidad y/o propaganda oficial para el cumplimiento de la sentencia. -

Esta sentencia fue recurrida tanto por la Provincia de Buenos Aires como por la Municipalidad de La Plata.

Es necesario mencionar que, mientras que la última providencia dictada en el Juzgado Contencioso Administrativo $\mathrm{N}^{\circ} 1$ fue el martes 2 de agosto de 2012, el "despacho" de autos para sentencia dictado por la Cámara Contenciosa Administrativa de La Plata fue el viernes 3 de agosto de ese año y, tan solo cuatro días después, el martes 7 de agosto, se dictó la sentencia, es decir en un solo día hábil. Esto es sumamente llamativo, ya que para ese entonces la causa contaba con 3.800 hojas que debían ser leídas por lxs tres juecxs integrantxs del tribunal, previo al dictado de la sentecia?.

Ese día Gustavo Daniel Spacarotel, Gustavo Juan De Santis y Claudia A.M. Milanta, todos ellos jueces de la Cámara en lo Contenciosa Administrativa revocaron los principales puntos de la sentencia de primera instancia.

Los jueces Spacarotel y Milanta, para dejar sin efecto de la creación del servicio hospitalario entendieron que el mismo "desborda innecesariamente los contornos medulares de la pretensión requerida por el actor. En efecto, la condena judicial

9 Datos extraídos del la Mesa de Entradas Virtual. 
carece de horizonte determinado que se corresponda con los perfiles necesarios para conformar un acto jurisdiccional con fuerza de verdad legal, involucrando un organismo administrativo (Ministerio de Salud) que no ha sido enjuiciado en autos".

Respecto de la afectación que se hacía sobre el presupuesto destinado a publicidad -para que el $25 \%$ sea destinado a difundir en los medios de comunicación los derechos de lxs niñxs-, los magistrados fundamentaron que "Una decisión judicial al respecto, no sólo desborda el principio republicano de gobierno, sino más aún, genera una fantasía y expectativa de imposible realización sustitutiva, toda vez que no resulta posible hacer efectiva una medida de tal naturaleza frente a la condición de posibilidad de inejecución administrativa, que obligase al Juez a discernir el manejo de fondos públicos discrecionalmente"

Por su parte, el juez De Santis entendió que había que recovar toda la sentencia bajo el entendimiento de que "Aprecio en el pronunciamiento recurrido, como en la misma articulación inicial, un propósito de sustitución de la función administrativa por la judicial que, por carente que pueda valorarse la primera desde el criterio político de sufragio del interés público, escapa a las posibilidades de la jurisdicción. Esta última siempre limitada a la inspección de legalidad de la conducta estatal de gestión, más nunca a su reemplazo... En orden a esas reglas constitutivas advierto en la sentencia pronunciada como en el intento de demanda un juicio de censura que avanza sobre la gestión que es inherente a la función administrativa a quien se le endilga ausencias en el ejercicio de su actividad constitucional, desde un ángulo de apreciación que deja ver criterios de eficacia y de disposición de recursos materiales y bumanos del estado en la consecución de la finalidad institucional de satisfacción del interés colectivo... Para más, el resultado jurisdiccional se aprecia como un conjunto de declaraciones sin la fuerza propia de ejecución de las sentencias judiciales, circunstancia ésta que deja ver en él las carencias de fuente 
que be descripto. Y, cuando lo hace accede al manejo directo de recursos presupuestarios" 10 .

Frente a esta sentencia, tanto la parte actora como los demandados, interpusieron recursos extraordinarios.

La parte actora -con el patrocinio letrado del Programa de Extensión Universitaria "Niñez, Derechos Humanos y Políticas Públicas" interpuso un recurso extraordinario de inaplicabilidad de ley exponiendo los siguientes agravios:

1. La transgresión por parte de la Cámara en lo Contencioso Administrativo de las normas aplicables al caso, concretamente, las prescripciones de la Convención Internacional sobre los Derechos del Niño; la ley 26.061; las leyes provinciales 13.634 y 13.298 y su decreto reglamentario 300/05. Ello en tanto la sentencia atacada, al hacer lugar parcialmente al recurso de apelación interpuesto por el señor Fiscal de Estado y revocar la sentencia de grado en relación a las prestaciones contenidas en los apartados 3.2. (crear un Servicio Hospitalario Especializado para la atención de la salud con niños con problemas de adicciones) y 3.6. (disponer la afectación porcentual de los recursos económicos para difundir las medidas protectorias otorgadas judicialmente), ha desconocido todo ese plexo normativo destinado a la protección de la niñez.

2. El Absurdo material en la aprehensión intelectual e interpretativa del contenido general de la pretensión de autos por parte de la Cámara en lo Contencioso Administrativo ya que, al revocar la prestación contenida en el apartado 3.2. del decisorio dictado por el magistrado de primera instancia, afirmando dogmáticamente -sin apoyo en las constancias de la causa- que tal fallo desbordó "innecesariamente los contornos medulares de la pretensión"; demostraba el absurdo en la errónea apreciación de la prueba;

\footnotetext{
10 ASOCIACION CIVIL MIGUEL BRU Y OTROSC/ MINISTERIO DE DESARROLLO SOC PCIA BS AS Y OTRO/A S/ AMPARO Sentencia de la Cámara de Apelaciones Contenciosa Administrativa 7 de agosto de 2012.
} 
3. La violación y/o aplicación errónea de la ley 13.298 y su decreto reglamentario $300 / 05$, en tanto el pronunciamiento impugnado -al revocar el punto 3.2. del fallo- que dicha prestación involucró a un organismo administrativo (Ministerio de Salud) que no había sido enjuiciado en autos. Asimismo, la existencia de absurdo interpretativo puesto que tal revocación judicial implicó descartar arbitrariamente la posibilidad de controlar judicialmente la normativa aplicable al caso en relación con la promoción de los derechos de la niñez;

4. La infracción al principio de congruencia, en tanto la Cámara habría vulnerado y/o aplicado erróneamente las mismas normas que invoca en el fallo que confirma, fragmentando el abordaje de la intervención del Estado, al confirmar algunos puntos y revocar otros, desconociendo así el sentido jurídico de integralidad, interdependencia e indivisibilidad de los derechos en juego a la par que desconoce la urgencia de las medidas invocadas, colocando nuevamente en situación de riesgo a los niños involucrados.

Sin embargo, pese a la interposición de tales recursos extraordinarios, desde finales del 2012, la causa esperó ser resuelta por la Suprema Corte de la Provincia de Buenos Aires (SCBA). Durante estos 8 años, se hicieron diversas presentaciones y se realizaron variados actos procesales que es necesario mencionar.

1. En el año 2014 el Sr. Adolfo Pérez Esquivel, premio Nobel de la Paz, presentó, junto con una serie de organizaciones de Derechos Humanos, un Amicus Curiae poniendo de manifiesto el incremento del presupuesto provincial destinado a la seguridad en detrimentro del presupuesto destinado a la niñez, así como también el agravamiento de las condiciones de detención de jóvenxs que se encontraban privadxs de su libertad.

2. El 30 de julio de 2016, se realizó una audiencia ante la SCBA donde la parte actora expuso acerca del estado de 
situación de lxs niñxs en situación de calle, la falta de políticas públicas y la insuficiente y deficiente aplicación de la política existente. Ante esta situación, la parte demandada no pudo hacer réplica alguna.

3. El 3 de mayo de 2019, la SCBA puso en conocimiento del Poder Ejecutivo la falta de implementación de la ley 13.298, a raíz de la preocupación manifestada por lxs Jueces de Familia del Departamento Judicial La Plata. Ante esta manifestación de la Suprema Corte y el empeoramiento de la situación de la niñez en la Provincia de Buenos Aires, y siendo que la la parte actora presentó un pronto despacho, exigiendo el dictado de la sentencia.

\section{Finalmente: la sentencia}

El 26 de febrero de 2020, la Suprema Corte Justicia de la Provincia de Buenos Aires dictó la esperada sentencia. En primer término se rechazaron los recursos interpuestos por la Municipalidad de La Plata por "insuficiencia impugnatoria".

En segundo término se abordó el tratamiento del recurso extraordinario de inaplicabilidad de ley planteado por lxs actorxs, haciendo lugar al mismo en forma parcial.

Para ello, el tribunal hizo un análisis diferenciado respecto de las cuestiones a tratar: por un lado, lo relativo al servicio hospitalario y, por el otro, a la difusión en los medios de comunicación.

Respecto a la primera cuestión, enunció que la Cámara de Apelaciones Contenciosa Administrativa de La Plata, en su sentencia, había desconocido la existencia del plexo normativo de derechos humanos que le corresponden a lxs niñxs. Por otro lado, la Cámara había manifestado que no se había demandado al Ministerio de Salud y que esto implicaba una violación al principio procesal de congruencia. A esta cuestión, la Suprema Corte remarca la errónea interpretación de este principio y la forma fragmentada de ver al Estado, desconociendo el sentido 
jurídico de integralidad del mismo. En esta línea, se dijo que la aplicación rigurosa del principio de congruencia violenta derechos consagrados constitucionalmente, que eran parte del objeto del amparo.

A su vez, el tribunal enunció que se había desconocido el derecho a la salud integral de lxs niñxs, no solo reconocida en tratados internacionales de derechos humanos, sino en la propia Constitución de la Provincia de Buenos Aires. En este sentido, la magistrada que encabezó el voto recordó el principio del interés superior del niño como principio rector en toda toma de decisiones que afecte la vida de niñxs y jóvenxs.

Respecto a la segunda cuestión, la SCBA señaló diferentes cuestiones.

En primer lugar, enunció que es absurdo que el tribunal utilice el plexo normativo de protección de derechos del niño como argumento para confirmar la mayoría de las prestaciones ordenadas por el Juez de primera instancia, y que luego rechace dos medidas que resultan parte de la misma solución integral. Esto deja en evidencia el desconocimiento por parte de la Cámara Contenciosa Administrativa de La Plata sobre el propio objeto del amparo.

En segundo lugar, el argumento utilizado por la Cámara para rechazar la pretensión de naturaleza presupuestaria fue decir que quien tiene el poder de ordenar en esta materia es exclusivamente el poder legislativo. Ante esta cuestión, el tribunal dice que el Estado no enunció un argumento en torno a demostrar que ha realizado esfuerzos para poder cumplir con sus obligaciones, requisito enunciado por el Comité Derechos Económicos Sociales y Culturales de la ONU. Agregó que además, en función del principio del interés superior del niño, las políticas públicas en materia de niñez tienen prioridad.

En tercer lugar, la SCBA difirió el porcentaje del presupuesto a destinar a la publicidad a que sea definido en el proceso de ejecución de sentencia. 
Por último, el Supremo Tribunal enunció que se está en presencia de un litigio de interés público y que ante el mismo hay que dejar de lado la clásica sentencia condenatoria del proceso tradicional, para abrir la posibilidad de buscar soluciones consensuadas por todas las partes involucradas. Para ello debe existir un diálogo donde se escuchen a todxs lxs participantxs $y$, principalmente, que se puedan crear soluciones que sean de real aplicación.

De esta menera, la SCBA confirmó la sentencia de primera instancia, ordenado la creacion y puesta en funcionamiento de un servicio hospitalario especializado para niñxs con problemas de adicciones y amplia difusión de los principios, derechos y garantías de lxs niñxs y adolescentxs consagrados por el ordenamiento jurídico, con asignación específica y prioritaria de recursos.

En este sentido, la sentencia dio una serie de reglas que deberán cumplirse en el proceso de ejecución de la sentencia:

1. La Provincia de Buenos Aires y la Municipalidad de La Plata deberán elaborar un plan detallado que deberá ser presentado ante el Juez de primera instancia en un plazo no mayor a 6 meses.

2. Los plazos y la modalidad de la condena serán objeto del proceso de ejecución de la sentencia.

3. Se le otorga al Juez de primera instancia la facultad para crear una comisión de seguimiento, control y monitoreo del proceso que deberá estar integrado por todas las partes y los organismos de derechos humanos que participaron del proceso.

\section{IV. ¿Y ahora?}

La sentencia de la Suprema Corte de la Provincia de Buenos Aires dictada el 26 de febrero de 2020 significa tanto el final de un ciclo como el comienzo de otro. 
Por un lado, se obtuvo un reconocimiento por parte del órgano judicial de mayor jerarquía de la Provincia de Buenos Aires respecto de la falta de implementación del sistema de promoción y protección de los derechos del niñx, así como también la condena al Estado Provincial y Municipal para que pongan en marcha este sistema y se le garanticen los todos derechos a todxs lxs niñxs.

Por otro lado, nos encontramos ante un enorme desafío: comienza el proceso de ejecución de una sentencia que ordena la plena implementación del sistema de promoción y protección, donde se tendrá que debatir acerca de cuáles van a ser las políticas públicas que se van a llevar a cabo, así como también cuándo, de qué forma y con qué presupuesto. Si bien en la sentencia la SCBA enunció algunos de los principios sobre los que se debía construir el proceso de ejecución de la sentencia, no existe ninguna norma en el Código Procesal que indique qué forma debe tener este proceso. Tampoco existen tantos precedentes, al menos en nuestro país, de litigios de interés público que hayan llegado a este estadío procesal.

A su vez, creemos de vital importancia la participación de niñxs, sus familias y lxs trabajadorxs de niñez en el proceso de ejecución de sentencia, para que sus voces sean escuchadas y sus opiniones sean tomadas en cuenta, ya que ellxs son lxs usuarixs del sistema de promoción y protección.

Desde 2008, cuando inició la cuasa, hemos podido observar innumerables situaciones de vulneración de derechos de niñxs y adolescentes que no han hallado respuestas integrales por parte de las instituciones del Sistema de Promoción y Protección de Derechos, y ello encuentra sus orígenes en características propias de las formas que ha construido el estado para asistir a la niñez. Se trata de respuestas fragmentadas, ausencia de recursos y insuficiencia de la política pública existente, precarización laboral de lxs trabajadorxs de niñez, dificultades en la coordinación de acciones corresponsables con otras instituciones, falta de información pública sobre el estado real de la 
niñez en la provincia y en la ciudad de La Plata, existencia de instituciones inaccesibles y centralizadas en los centros urbanos que no se condicen con las necesidades de cada barrio, retaceo de información a lxs niñxs y sus familias sobre medidas que se llevan a cabo, entre otras cosas. Por ello es que entendemos que la ejecución integral de la sentencia de este amparo resulta imprescindible, la niñez ya no puede esperar, es ahora.

Por último, no podemos dejar de mencionar a todas las personas que pusieron el cuerpo y que lucharon para alcanzar esta sentencia. En primero lugar a lxs niñxs, a lxs pibxs de la plaza, a sus familias, a las inumerables organizaciones sociales que trabajan día a día con lxs pibxs, a las facultades de Trabajo Social y de Cs. Jurídicas y Sociales de la UNLP, a la Comisión Provincial por la Memoria y a todxs lxs compañerxs. 